\title{
POPULAÇÃO MICROBIANA TOTAL E SOLUBILIZADORA DE FOSFATO EM SOLO SUBMETIDO A DIFERENTES SISTEMAS DE CULTIVO'
}

\author{
GIOVANE BARROTI² e ELY NAHAS ${ }^{3}$
}

\begin{abstract}
RESUMO - O objetivo deste trabalho foi avaliar o efeito de diferentes espécies de plantas, fontes de fósforo e calagem sobre a população microbiana total e solubilizadora de fosfato. Foram isolados fungos e bactérias capazes de solubilizar hidroxiapatita, proporcionando $\mathrm{P}$ solúvel. O experimento utilizado foi em blocos ao acaso com fatorial $3 \times 3 \times 2$. E os fatores avaliados foram espécies de plantas (controle, braquiária e guandu), fertilizantes (controle, superfosfato simples e fosfato de rocha, ambos na dose de $400 \mathrm{~kg} \mathrm{ha}^{-1}$ de $\mathrm{P}_{2} \mathrm{O}_{5}$ ) e calagem (com e sem calcário). A população bacteriana cresceu pelo efeito da calagem, e a de fungos aumentou, independentemente da calagem, nas parcelas cultivadas com braquiária e fertilizadas com superfosfato. Foi constatado incremento de biomassa-P microbiana sobre o controle por influência da braquiária $(23,9 \%)$, do superfosfato $(30,9 \%)$ e da calagem $(46,9 \%)$. O número de bactérias solubilizadoras foi favorecido pela calagem ou pelo plantio de guandu adubado com fosfato natural ou com braquiária sem adubação. Os fungos solubilizadores aumentaram na ausência de planta ou de adubação e na presença de guandu com fosfato natural. Finalmente, a calagem favoreceu mais o crescimento dos fungos solubilizadores, em comparação com o controle, nos tratamentos fosfato natural, braquiária ou guandu.
\end{abstract}

Termos para indexação: braquiária, guandu, bactérias, fungos, biomassa.

\section{TOTAL MICROBIAL AND PHOSPHATE-SOLUBILIZING POPULATION IN SOIL SUBMITTED TO DIFFERENT CULTIVATION SYSTEMS}

\begin{abstract}
The objective of the present study was to evaluate the effect of different plant species, phosphorus sources, and liming on the total microbial and phosphate-solubilizing population. In order to achieve that, bacteria and fungi capable of solubilizing hydroxyapatite providing available $\mathrm{P}$ were isolated. An experiment was carried out in a randomized factorial block design $3 \times 3 \times 2$. The factors evaluated were plant species (control, Brachiaria ruziziensis and Cajanus cajan), fertilizers (control, simple superphosphate and rock phosphate, both at the dose of $400 \mathrm{~kg} \mathrm{ha}^{-1}$ of $\mathrm{P}_{2} \mathrm{O}_{5}$ ) and liming (with and without lime). While the bacterial population increased due to the effect of liming, the fungal population also increased independently of liming in the soil cultivated with B. ruziziensis and fertilized with superphosphate. An increase of the microbial biomass-P compared to the control was observed under the influence of B. ruziziensis (23.9\%), superphosphate (30.9\%) or liming (46.9\%). The number of solubilizing bacteria was favored by liming and by the planting of $C$. cajan fertilized with rock phosphate or with unfertilized B. ruziziensis. The solubilizing fungi increased in the absence of plants or fertilization and in the presence of $C$. cajan fertilized with rock phosphate. Finally, liming enhanced more the growth of solubilizing fungi than did the control in the treatments using rock phosphate, B. ruziziensis or C. cajan.
\end{abstract}

Index terms: Brachiaria ruziziensis, Cajanus cajan, bacteria, fungi, biomass.

${ }^{1}$ Aceito para publicação em 21 de janeiro de 2000.

Extraído da dissertação de mestrado do primeiro autor. Trabalho financiado pela FAPESP.

${ }^{2}$ Lic. em Química, Dep. de Química, Fundação Educacional de Barretos (FACIBA), Rua 14, 01747, CEP 14780-000 Barretos, SP. E-mail: barroti@barretos.com.br

${ }^{3}$ Eng. Agrôn., Prof. Titular, Dep. de Horticultura, Lab. de Microbiologia do Solo, Faculdade de Ciências Agrárias e Veterinárias (FCAV), Universidade Estadual Paulista (UNESP), Rod. Carlos Tonnani, km 5, CEP 14870-000 Jaboticabal, SP. E-mail: enahas@fcav.unesp.br.

\section{INTRODUÇÃO}

Entre os elementos essenciais, o fósforo (P), logo após o nitrogênio $(\mathrm{N})$, ocupa posição de destaque em relação aos seres vivos, tendo em vista sua atuação estrutural, funcional, e na transferência de energia (Nahas, 1991). Considerável número de trabalhos têm sido desenvolvidos num esforço de encontrar alternativas para suprir as necessidades de $\mathrm{P}$ para as plantas a um custo menor, e nesse sentido muitas 
das pesquisas estudaram a possibilidade de aplicação direta dos fosfatos naturais no solo (Bolland \& Gilkes, 1995; Omar, 1998), que, no entanto, apresentam limitações na disponibilidade de P. Por isso, são recomendados na formação e manutenção de pastagens e capineiras, em reflorestamentos e na formação de culturas perenes (Lopes \& Goedert, 1987). Nas culturas anuais, a eficiência desses fosfatos deixa a desejar, pois se manifesta somente após longo período de tempo (Goedert, 1983).

Por outro lado, foi comprovada a presença de microrganismos do solo com capacidade de solubilizar fosfatos naturais, propiciando fosfato solúvel além das suas necessidades, que é aproveitado pelas plantas. Esses resultados propiciaram o desenvolvimento de programas de inoculação de microrganismos solubilizadores de fosfatos, com resultados favoráveis (Young, 1990). Contudo, carecem de perspectiva quando considerados extensivamente. Dessa forma, a pesquisa das condições de crescimento desses microrganismos no solo constitui um potencial a ser explorado.

A presença de microrganismos solubilizadores tem sido constatada na maioria dos solos investigados (Jones et al., 1991; Nahas et al., 1994), e alguns fatores que influenciaram seu crescimento foram estudados. Tem sido assinalado que o tipo de solo, a espécie e a idade da planta afetaram o processo de solubilização (Odunfa \& Oso, 1978). Entre as plantas cultivadas, foi constatada maior presença de bactérias solubilizadoras em leguminosas do que em gramíneas (Sylvester-Bradley et al., 1982). Na rizosfera de Trifolium alexandrinum e Phaseolus aureus, foi verificado maior número de microrganismos solubilizadores de fosfato do que na rizosfera de Crotalaria juncea e de Sesbania aculeata (Paul \& Rao, 1971). A população de microrganismos solubilizadores variou de $10^{5}$ a $10^{6}$ células $\mathrm{g}^{-1} \mathrm{de}$ solo seco em leguminosas forrageiras (Rosa et al., 1982), e de $10^{3}$ a $10^{6}$, em gramíneas forrageiras (Sandoval et al.,1982). O manejo agrícola contribuiu no tamanho e atividade da população microbiana (Bolton Junior et al., 1985; Fraser et al., 1988; Kirchner et al., 1993 ).

Contudo, segundo Bossio et al. (1998), os fatores que regulam a composição da população microbiana, e, por conseguinte, o seu efeito na produtividade agrícola, não são, ainda, plenamente conhecidos. Com relação aos microrganismos solubilizadores, os dados da literatura dão mais ênfase às bactérias do que aos fungos, que são potencialmente mais promissores no processo de solubilização de fosfato. Além disso, não levaram em consideração os fatores mais comumente estudados em um experimento agrícola, como planta, adubação e calagem.

Este trabalho objetivou verificar o efeito de uma gramínea e de uma leguminosa, de uma fonte de $\mathrm{P}$ solúvel e outra insolúvel, em solo com ou sem aplicação de calcário, sobre os microrganismos totais e solubilizadores de fosfato insolúvel.

\section{MATERIAL E MÉTODOS}

O experimento foi instalado em um Latossolo Vermelho-Escuro, textura arenosa, na Fazenda Boa Esperança de Minas, em Comendador Gomes, MG. A precipitação pluvial média anual foi de $1.435 \mathrm{~mm}$. O solo apresentou a seguinte composição: M.O. $=1,5 \mathrm{~g} \mathrm{~kg}^{-1} ; \mathrm{P}=4 \mathrm{mg} \mathrm{dm}^{-3}$; $\mathrm{pHem} \mathrm{CaCl} 2=4,5$; cátions trocáveis em $\operatorname{mmol}_{\mathrm{c}} \mathrm{dm}^{-3}: \mathrm{Ca}=$ 0,$9 ; \mathrm{Mg}=0,4 ; \mathrm{K}=0,05$ e $\mathrm{Al}=0,18$. A CTC a pH 7,0 de $3,75 \mathrm{mmol}_{\mathrm{c}} \mathrm{dm}^{-3}$, e saturação por bases $36,0 \%$.

Foi utilizado um experimento em blocos ao acaso em fatorial $3 \times 3 \times 2$, com duas repetições. Cada parcela mediu $18 \mathrm{~m}^{2}$. Os fatores analisados foram: plantas (gramínea, Brachiaria ruziziensis, leguminosa, Cajanus cajan (L.) Millsp.; e ausência de planta), adubos (superfosfato simples, fosfato natural de Araxá e ausência de adubo), e calagem (com e sem calagem). Foram feitas duas arações e duas gradagens, seguidas da calagem e da adubação. Foram aplicados $400 \mathrm{~kg} \mathrm{ha}^{-1}$ de $\mathrm{P}_{2} \mathrm{O}_{5}$ e 1,3 tha ${ }^{-1}$ de calcário. Aos 30 dias, foram aplicados $60 \mathrm{~kg} \mathrm{ha}^{-1} \mathrm{de} \mathrm{N}$ em cobertura. Após a semeadura, as parcelas foram carpidas a cada 20 dias.

Foram retiradas amostras de solo de dez pontos de cada parcela, na profundidade de zero a $20 \mathrm{~cm}$ e foram reunidas e estendidas em bandeja, para separação de material estranho (raízes, pedaços de madeira, folhas), peneiradas em peneira de malha de $2 \mathrm{~mm}$, e armazenadas em geladeira até o momento de utilização.

Na contagem dos microrganismos, foi utilizado o procedimento de diluição em série (Wollum, 1982), utilizando-se meio de Bunt \& Rovira (1955), pH 7,4, para contagem de bactérias, e meio de Martin (1950), $\mathrm{pH} 5,6$, acrescido de $60 \mu \mathrm{g} \mathrm{mL}^{-1}$ de penicilina, $40 \mu \mathrm{g} \mathrm{mL}^{-1} \mathrm{de}$ estreptomicina e $70 \mu \mathrm{g} \mathrm{mL}^{-1}$ de rosa bengala, para contagem de fungos. As placas foram incubadas à temperatura de $30^{\circ} \mathrm{C}$ por 24 horas (bactérias) e 72 horas (fungos). Com base nas características fenotípicas das colônias, foram 
isolados 40 fungos e 50 bactérias por placa. Os isolados foram cultivados em tubos contendo meio BDYA (batata, dextrose, extrato de levedura e ágar) $\mathrm{pH} 7,0$, para bactérias, e $\mathrm{pH} 5,5$, para fungos, à temperatura de $30^{\circ} \mathrm{C}$ por $2-5$ dias (Kucey, 1983) e, a seguir, conservados em geladeira à temperatura de $4^{\circ} \mathrm{C}$ pelo período máximo de 30 dias, e então, foram renovados.

Na contagem de microrganismos solubilizadores, foi utilizado o procedimento de Nahas et al. (1994), e na identificação dos solubilizadores de fosfato inorgânico, empregou-se o mesmo meio de isolamento, $\mathrm{pH} 7,0$, acrescido de fosfato precipitado (Sperber, 1958) . A formação de uma zona clara em volta da colônia caracterizou os microrganismos solubilizadores. Após o crescimento, foram medidos o diâmetro da colônia e do halo.

Para a determinação do $\mathrm{P}$ da biomassa microbiana e do $\mathrm{pH}$ do solo, foram utilizados, respectivamente, os métodos de Brookes et al.(1982) e de Raij et al. (1987).

\section{RESULTADOS E DISCUSSÃO}

A calagem foi o único efeito estatisticamente significativo (teste $\mathrm{F}, \mathrm{P}<0,01$ ) que favoreceu o crescimento bacteriano; em média, constatou-se um aumento de $24,1 \%$ nas contagens das unidades formadoras de colônias (UFC) sobre os tratamentos que não receberam calcário (Tabela 1). Nenhum efeito foi constatado sobre o número de fungos, a não ser nas interações dos fatores analisados. Independentemente de calagem ou não, observou-se um aumento maior do número de colônias de fungos nas parcelas cultivadas com braquiária e fertilizadas com superfosfato, do que nos demais tratamentos. Além disso, nas parcelas isentas de plantas, quando não foi realizada adubação, ocorreu incremento do número de fungos, sobrepujando os outros tratamentos.

A ausência da influência da adubação fosfatada sobre o número de bactérias de solos, cultivados ou não, também foi notada por Sagardoy \& Salerno (1983). Diferentemente, Nuernberg et al. (1984) mostraram que o número de microrganismos foi dependente da adubação, obtendo-se maior população em solo com adubação mineral ou organomineral em relação ao controle (não adubado). Nahas \& Assis (1991) mostraram que o número de fungos, diferentemente das bactérias, não se alterou em resposta à incorporação de nutrientes no solo. Utilizando-se diferentes sistemas de culturas, também não foi encontrada variação no número de fungos e nenhum efeito significativo pelo teor de P (Cattelan \& Vidor, 1990).

Diferentemente dos fungos, as bactérias cresceram como resultado da calagem do solo, ou, em outros termos, em decorrência do aumento do $\mathrm{pH}$, inclusive confirmado pela significativa análise de correlação $(r=0,63, P<0,01)$, mostrada na Fig. 1 . Respostas obtidas na literatura mostraram uma relação linear entre as contagens de bactérias com os valo-

TABELA 1. Número de bactérias e fungos em solo submetido a diferentes sistemas de cultivo'

\begin{tabular}{|c|c|c|c|c|c|c|}
\hline \multirow[t]{2}{*}{ Planta } & \multicolumn{3}{|c|}{ Bactérias } & \multicolumn{3}{|c|}{ Fungos } \\
\hline & Controle & Superf. simples & Fosfato de rocha & Controle & Superf. simples & Fosfato de rocha \\
\hline & \multicolumn{3}{|c|}{----- (No UFC x $10^{6} \mathrm{~g}^{-1}$ solo seco) ------ } & \multicolumn{3}{|c|}{ - } \\
\hline $\begin{array}{l}\text { Sem calagem } \\
\text { Controle }\end{array}$ & 6.94 & 600 & 670 & 1440 & 911 & 1405 \\
\hline Braquiária & 7,53 & 9,09 & 7,41 & $\begin{array}{l}14,40 \\
10,24\end{array}$ & 17,55 & $\begin{array}{r}14,0 J \\
9,36\end{array}$ \\
\hline Guandu & 6,39 & 7,77 & 6,70 & 10,66 & 12,03 & 12,14 \\
\hline \multicolumn{7}{|l|}{ Com calagem } \\
\hline Controle & 9,19 & 11,65 & 8,07 & 20,36 & 14,67 & 9,27 \\
\hline Braquiária & 9,67 & 11,45 & 7,06 & 9,42 & 19,04 & 10,12 \\
\hline Guandu & 6,96 & 8,66 & 7,37 & 14,11 & 12,32 & 15,17 \\
\hline
\end{tabular}

${ }^{1}$ A análise de variância foi feita com base nos dados transformados em logaritmo; valores de F para bactérias: planta (A), 1,94ns; adubo (B), 3,17 ${ }^{\text {ns }}$;

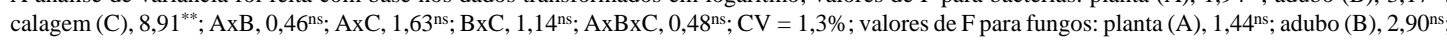

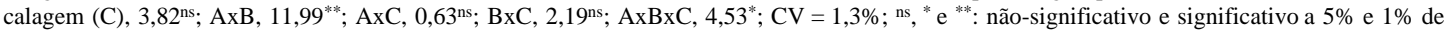
probabilidade, respectivamente. 
res de pH (Sagardoy \& Salerno, 1983) porém não com as de fungos (Cattelan \& Vidor, 1990). Aumento do número de bactérias aeróbias e uma redução do número de fungos e leveduras foi também observado por efeito da calagem (El-Tarabily et al., 1996). Enquanto as bactérias se desenvolvem em uma estreita faixa de $\mathrm{pH}$ mais próxima da neutralidade, os fungos desenvolvem-se bem em ambiente ácido em uma faixa mais ampla de $\mathrm{pH}$ (Alexander, 1977). Essas características explicam por que as bactérias responderam ao aumento do $\mathrm{pH}$, ao passo que os fungos não responderam.

Os resultados reunidos na Tabela 2 mostram que tanto a planta e o adubo como a calagem influíram sobre a biomassa-P microbiana. Assim, foi verificado um aumento sobre o controle de $15 \%$ a $31 \%$ em

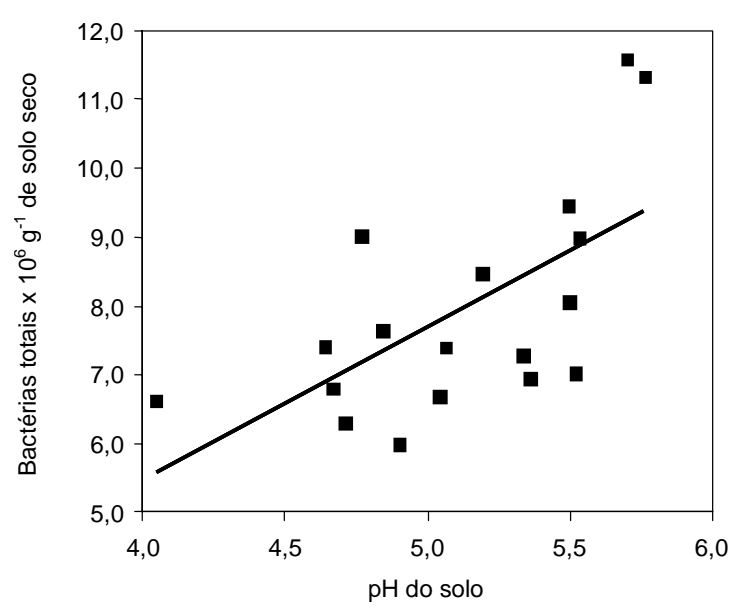

FIG. 1. Efeito do pH do solo sobre o número de bactérias. A análise de correlação foi realizada com os dados dos números de bactérias totais transformados para logaritmo $(y=0,1138 x-6,3108$, $R=0,6303$ ). resposta à adubação com fosfatos, de $9 \%$ a $24 \%$ ao cultivo com as plantas, e de $47 \%$ à calagem. Em decorrência desses fatos, a significativa interação (Tukey, $\mathrm{P}<0,05$ ) observada na Tabela 2 comprova que houve aumento da biomassa-P microbiana apenas onde foi feita calagem e aplicado fosfato. Também, não se constataram diferenças nos valores da biomassa-P microbiana entre os fertilizantes, nos solos onde não foi feita calagem. Acréscimo de aproximadamente $30 \%$ por efeito da calagem na biomassaC e biomassa- $\mathrm{N}$ foi também obtido em solo de diferentes gramíneas (Adams \& Adams, 1983). Relatos da literatura apontam para um aumento da biomassa$\mathrm{P}$ em relação ao controle pela adubação com superfosfato, porém não com fosfato natural em braquiária (Guerra et al., 1995), o que concorda com os resultados obtidos no presente trabalho, e com diferentes fertilizantes em arroz e lentilha (Srivastava \& Singh, 1991). Contudo, em floresta de abeto, adubação com P, K por 20 anos apresentou valor correspondente à metade do obtido no controle em solos onde foi aplicado somente N (Clarholm, 1993).

Aumento da biomassa-P como resultado da adubação sugere uma resposta ao crescimento microbiano. Entretanto, a análise estatística mostrou que nem a população bacteriana e nem a fúngica responderam à adubação, embora tenha sido constatado aumento do número de bactérias em solo adubado com superfosfato e cultivado com braquiária ou com guandu (Tabela 1). Este aumento da população bacteriana pode ter resultado na correlação $(\mathrm{r}=0,56, \mathrm{P}<0,05)$ significativa com a biomassa-P (Fig. 2). Da mesma forma, tanto o número de bactérias totais (Tabela 1) como a biomassa-P (Tabela 2) responderam significativamente à calagem $(\mathrm{P}<0,01)$. Como conseqüência, foram obtidos os coeficientes de correlação estatisticamente significativos entre o

TABELA 2. Biomassa-P microbiana em solo submetido a diferentes sistemas de cultivo'.

\begin{tabular}{|c|c|c|c|c|c|c|}
\hline \multirow[t]{2}{*}{ Planta } & \multicolumn{3}{|c|}{ Sem calagem } & \multicolumn{3}{|c|}{ Com calagem } \\
\hline & Sem adubo & Superf. simples & Fosfato de rocha & Sem adubo & Superf. simples & Fosfato de rocha \\
\hline & \multicolumn{6}{|c|}{ 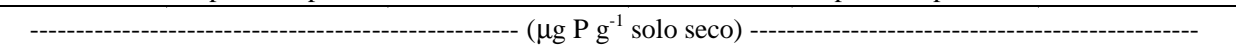 } \\
\hline Sem planta & 5,10 & 2,37 & 4,03 & 3,57 & 7,29 & 5,25 \\
\hline Braquária & 3,93 & 4,63 & 4,23 & 4,15 & 8,15 & 4,88 \\
\hline Guandu & 3,86 & 4,61 & 4,41 & 5,95 & 7,69 & 7,67 \\
\hline
\end{tabular}

${ }^{1}$ Valores de F: para planta (A), 4,09*; adubo (B), 6,16**; calagem (C), 37,08**; AxB, 1,48 ${ }^{\text {ns. }}$ AxC, $1,89^{\text {ns }} ;$ BxC, $10,68^{* *} ; A x B x C, 2,39^{\text {nss }} ; C V=18,7 \%$; ns,${ }^{*} \mathrm{e}^{* *}$ : não-significativo e significativo a $5 \%$ e $1 \%$ de probabilidade, respectivamente. 
número de bactérias totais $(\mathrm{r}=0,63, \mathrm{P}<0,01)$ ( Fig. 1$)$, a biomassa-P microbiana $(\mathrm{R}=0,51, \mathrm{P}<0,05)($ Fig. 3$) \mathrm{e}$ o índice de $\mathrm{pH}$.

As bactérias solubilizadoras foram influenciadas apenas pelo fator planta, e os valores encontrados no solo de guandu foram inferiores aos dos demais tratamentos (Tabela 3). Considerando-se as

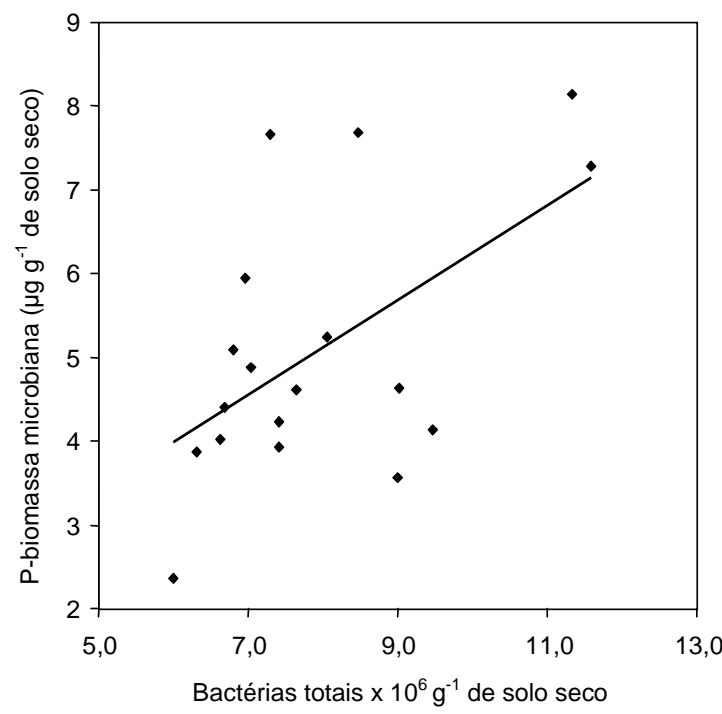

FIG. 2. Correlação entre o número de bactérias totais sobre biomassa-P microbiana. A análise de correlação foi realizada com os dados dos números de bactérias totais transformados para logaritmo $(y=11,068 x-71,196$, $\mathbf{R}=\mathbf{0 , 5 5 7 2}$ ). interações estatisticamente significativas (Tukey, $\mathrm{P}<0,05)$, o número de bactérias solubilizadoras foi favorecido quando foi feito o plantio de guandu adubado com fosfato natural e de braquiária sem adubação. Também os tratamentos com calagem na ausência de planta, ou na presença de guandu, foram superiores aos correspondentes sem calagem. Esses resultados comparam-se aos obtidos por Sylvester-Bradley et al. (1982) e Machado et al. (1983), que obtiveram aumento da contagem de bactérias solubilizadoras por efeito do cultivo de leguminosas e da adubação com fosfato natural, respectivamente. Contudo, diferem dos obtidos por Louw \&

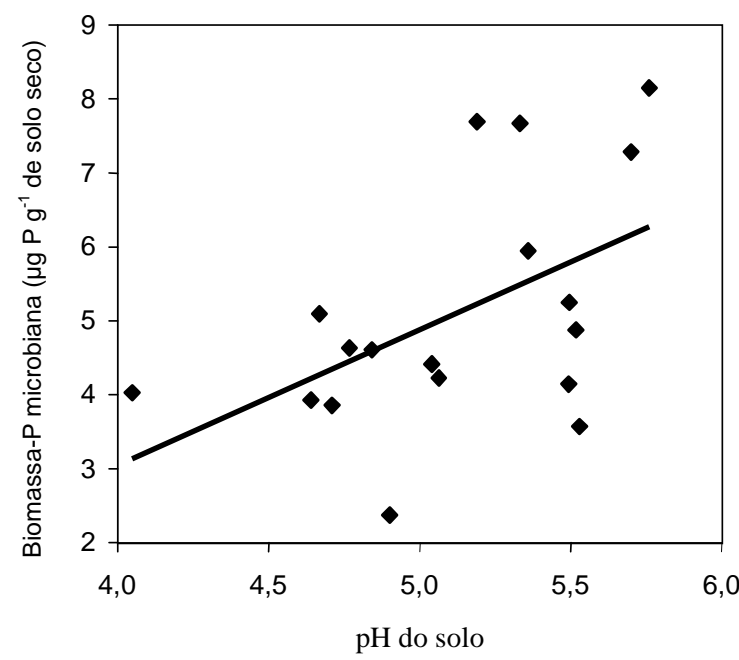

FIG.3. Efeito do $\mathrm{pH}$ do solo sobre a biomassa-P microbiana $(y=1,8339 x-4,2832, R=0,5113)$.

TABELA3. Contagem de bactérias e fungos solubilizadores de fosfato insolúvel em solo submetido a diferentes sistemas de cultivo ${ }^{1}$.

\begin{tabular}{|c|c|c|c|c|c|c|}
\hline \multirow[t]{2}{*}{ Planta } & \multicolumn{3}{|c|}{ Bactérias } & \multicolumn{3}{|c|}{ Fungos } \\
\hline & Controle & Superf. simples & Fosfato de rocha & Controle & Superf. simples & Fosfato de rocha \\
\hline & & & $\left(\mathrm{N}^{\mathrm{O}}\right.$ UFC x & $\mathrm{g}^{-1}$ solo se & 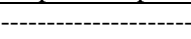 & 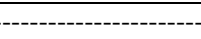 \\
\hline \multicolumn{7}{|l|}{ Sem calagem } \\
\hline Controle & 2,91 & 1,44 & 2,28 & 6,18 & 3,42 & 4,92 \\
\hline Braquiária & 3,69 & 2,23 & 2,62 & 2,11 & 4,49 & 0,52 \\
\hline Guandu & 1,14 & 2,10 & 1,78 & 3,55 & 1,85 & 3,37 \\
\hline \multicolumn{7}{|l|}{ Com calagem } \\
\hline Controle & 2,02 & 4,19 & 2,47 & 4,82 & 2,38 & 1,50 \\
\hline Braquiária & 3,35 & 1,91 & 2,16 & 1,05 & 2,17 & 3,46 \\
\hline Guandu & 2,03 & 1,55 & 3,17 & 5,33 & 3,77 & 3,03 \\
\hline
\end{tabular}

${ }^{1}$ A análise de variância foi feita com base nos dados transformados em logaritmo; valores de F para bactérias: planta (A), 8,40**; adubo (B), 1,40 ${ }^{\text {ns; }}$ calagem (C), 3,71 $1^{\mathrm{ns}} ; \mathrm{AxB}, 5,17^{* *} ; \mathrm{AxC}, 4,27^{*} ; \mathrm{BxC}, 0,48^{\mathrm{ns}} ; \mathrm{AxBxC}, 9,22^{* *} ; \mathrm{CV}=1,4 \%$; valores de $\mathrm{F}$ para fungos: planta (A), 90,74**; adubo (B),

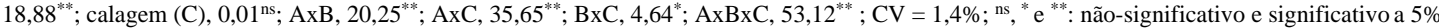
e $1 \%$ de probabilidade, respectivamente. 
Webley (1959), que verificaram maior influência do superfosfato que do fosfato bicálcico.

Todos os fatores analisados pelo teste $\mathrm{F}(\mathrm{P}<0,01)$, exceto a calagem e as respectivas interações (Tukey, $\mathrm{P}<0,05)$ influíram nos números de fungos solubilizadores (Tabela 3). As melhores respostas foram obtidas na ausência de plantio e/ou de adubação $(\mathrm{P}<0,01)$. Efeito significativo foi obtido quando se associou o guandu ao fosfato de rocha. $\mathrm{Na}$ ausência de calagem, maior número de solubilizadores foi encontrado nos tratamentos sem adubo $>$ superfosfato $>$ fosfato natural e sem planta $>$ guandu > braquiária. Na presença de calagem, verificaram-se as seguintes respostas: guandu > sem planta > braquiária, e o efeito da adubação foi estatisticamente similar. Quando não foi feita calagem, os tratamentos sem adubo, superfosfato e sem planta apresentaram maiores valores que os correspondentes com calagem. Os tratamentos fosfato natural, braquiária e guandu propiciaram maior crescimento aos fungos quando foi feita a calagem, do que os correspondentes sem calagem.

\section{CONCLUSÕES}

1. O número de bactérias totais aumenta em decorrência da calagem; o número de fungos aumenta pelo plantio de braquiária associada ao superfosfato ou na ausência de planta e de adubo.

2. A biomassa-P microbiana aumenta em razão da calagem, do plantio de braquiária ou da adubação com superfosfato.

3. As bactérias solubilizadoras são favorecidas pela calagem, pelo plantio de guandu adubado com fosfato de rocha ou pelo plantio da braquiária sem adubação; são favorecidos os fungos solubilizadores principalmente na ausência de plantio ou da adubação fosfatada e quando se associa o guandu ao fosfato de rocha.

\section{REFERÊNCIAS}

ADAMS, T.M.; ADAMS, S.N. The effects of liming and soil $\mathrm{pH}$ on carbon and nitrogen contained in the soil biomass. Journal of Agricultural Science, Cambridge, Grã-Bretanha, v.101, n.3, p.553-558, 1983.
ALEXANDER, M. Introduction to soil microbiology. New York : J. Wiley, 1977. 467p.

BOLLAND, M.D.A.; GILKES, R.J. Long-term residual value of North Carolina and Queensland rock phosphates compared with triple superphosphate. Fertilizer Research, Dordrecht, v.41, n.2, p.151158,1995 .

BOLTON JUNIOR, H.; ELLIOTT, L.F.; PAPENDICK, R.I.; BEZDICEK, D.F. Soil microbial biomass and selected soil enzyme activities: effect of fertilization and cropping practices. Soil Biology \& Biochemistry, Oxford, v.17, n.3, p.297-302, 1985.

BOSSIO, D.A.; SCOW, K.M.; GUNAPALA, N.; GRAHAM, K.J. Determinants of soil microbial communities: effects of agricultural management, season, and soil type on phospholipid fatty acid profiles. Microbial Ecology, New York, v.36, n.1, p.1-12, 1998.

BROOKES, P.C.; POWLSON, D.S.; JENKINSON, D.S. Measurement of microbial biomass phosphorus in soil. Soil Biology \& Biochemistry, Oxford, v.14, n.4, p.319-329, 1982.

BUNT, J.S.; ROVIRA, A.D. Microbiological studies of some subantartic soils. Journal of Soil Science, Oxford, v.6, p.119-128, 1955.

CATTELAN, A.J.; VIDOR, C. Sistemas de culturas e a população microbiana do solo. Revista Brasileira de Ciência do Solo, Campinas, v.14, n.2, p.125132, 1990.

CLARHOLM, M. Microbial biomass P, labile P, and acid phosphatase activity in the humus layer of a spruce forest, after repeated additions of fertilizers. Biology and Fertility of Soils, Berlin, v.16, n.4, p.287-292, 1993.

EL-TARABILY, K.A.; HARDY, G.E.S.J.; SIVASITHAMPARAM, K.; KURTBOKE, I.D. Microbiological differences between limed and unlimed soils and their relationship with cavity spot disease of carrots (Daucus carota L.) caused by Pythium coloratum in Western Australia. Plant and Soil, Dordrecht, v.183, n.2, p.279-290, 1996.

FRASER, D.G.; DORAN, J.W.; SAHS, W.W.; LESOING, G.W. Soil microbial population and activities under conventional and organic management. Journal of Environmental Quality, Madison, v.17, p.585-590, 1988. 
GOEDERT, W.J. Efeito residual de fosfatos naturais em solos de cerrado. Pesquisa Agropecuária Brasileira, Brasília, v.18, n.5, p.499-506, 1983.

GUERRA, J.G.M.; FONSECA, M.C.C.; ALMEIDA, D.L.; DE-POLLI, H.; FERNANDES, M.S. Conteúdo de fósforo da biomassa microbiana de um solo cultivado com Brachiaria decumbens Stapf. Pesquisa Agropecuária Brasileira, Brasília, v.30, n.4, p.543-551, 1995.

JONES, D.; SMITH, B.F.L.; WILSON, M.J.; GOODMAN, B.A. Phosphate solubilizing fungi in a Scottish upland soil. Mycological Research, Cambridge, Grã-Bretanha, v.95, n.9, p.1090-1093, 1991.

KIRCHNER, M.J.; WOLLUM, A.G.; KING, L.D. Soil microbial populations and activities in reduced chemical input agroecosystems. Soil Science Society of America. Journal, Madison, v.57, n.5, p.1289-1295, 1993.

KUCEY, R.M.N. Phosphate-solubilizing bacteria and fungi in various cultivated and virgin Alberta soils. Canadian Journal of Soil Science, Ottawa, v.63, n.4, p.671-678, 1983

LOPES, A.C.; GOEDERT, W.J. Eficiência agronômica de fertilizantes fosfatados para culturas anuais, perenes, pastagens e reflorestamento. In: SEMINÁRIO SOBRE RECUPERAÇÃO DE FÓSFORO, 1987, São Paulo. [Trabalhos apresentados]. São Paulo : Ibrafos, 1987. p.24-49.

LOUW, H.A.; WEBLEY, D.M. The bacteriology of the root region of the oat plant growth under controled pot culture conditions. Journal of Applied Bacteriology, Oxford, v.22, n.2, p.216-226, 1959.

MACHADO, J.O.; PICCIN, C.R.; BARBOSA, J.C.; NAHAS, E. Ação da vinhaça e fosfato natural sobre a população de bactérias solubilizadoras de fosfato bicálcico, habitantes de rizosfera de Lycopersicon esculentum (Mill.) cv. "Petomech". Científica, Jaboticabal, v.11, n.1, p.63-69, 1983.

MARTIN, J.P. Use of acid, rose bengal, and streptomycin in the plate method for estimating soil fungi. Soil Science, Baltimore, v.69, p.215-232, 1950.

NAHAS, E. Ciclo do fósforo: transformações microbianas. Jaboticabal : FUNEP, 1991. 67p.

NAHAS, E.; ASSIS, L.C. Efeito da adição ao solo de fosfato solúvel obtido por via microbiológica a partir de fluorapatita. Revista Latinoamericana de
Microbiologia, México, v.33, n.2/3, p.225-229, 1991.

NAHAS, E.; CENTURION, J.F.; ASSIS, L.C. Microrganismos solubilizadores de fosfato e produtores de fosfatases de vários solos. Revista Brasileira de Ciência do Solo, Campinas, v.18, n.1, p.43-48, 1994.

NUERNBERG, N.J.; VIDOR, C.; STAMMEL, J.G. Efeito de sucessões de culturas e tipos de adubação na densidade populacional e atividade microbiana do solo. Revista Brasileira de Ciência do Solo, Campinas, v.8, n.2, p.197-203, 1984.

ODUNFA, V.S.A.; OSO, B.A. Bacterial population in the rhizosphere soils of cowpea and sorghum. Revue d'Ecologie et de Biologie du Sol, Paris, v.15, n.4, p.413-420, 1978.

OMAR, S.A. The role of rock-phosphate-solubilizing fungi and vesicular-arbuscular-mycorrhiza (VAM) in growth of wheat plants fertilized with rock phosphate. World Journal of Microbiology and Biotechnology, London, v.14, n.2, p.211-218, 1998.

PAUL, N.B.; RAO, W.V.B.S. Phosphate-dissolving bacteria in the rhizosphere of some cultivated legumes. Plant and Soil, Dordrecht, v.35, n.1, p.127$132,1971$.

RAIJ, B. van; QUAGGIO, J.A.; CANTARELLA, H.; FERREIRA, M.E.; LOPES, A.S.; BATAGLIN, O.C. Análise química do solo para fins de fertilidade. Campinas : Fundação Cargill, 1987. 170p.

ROSA, F.V.; MACHADO, J.O.; SANDOVAL, C.R.; BARBOSA, J.C. Densidade de microrganismos solubilizadores de fosfato dicálcico em solo de rizosfera de algumas leguminosas forrageiras. Científica, Jaboticabal, v.10, n.2, p.209-216, 1982.

SAGARDOY, M.A.; SALERNO, C.M. Number, distribuition, and characterization of heterotrophic bacteria in some Argentine soils. Anales de Edafologia y Agrobiologia, Madrid, v.42, p.20692081, 1983.

SANDOVAL, C.R.; MACHADO, J.O.; ROSA, F.V.; BARBOSA, J.C. Densidade de microorganismos solubilizadores de fosfato dicálcico em solo de rizosfera de quatro espécies de gramíneas forrageiras. Científica, Jaboticabal, v.10, n.1, p.25-33, 1982.

SPERBER, J.I. The incidence of apatite-solubilizing organisms in the rhizosphere and soil. Australian Journal of Agricultural Research, Collingwood, v.9, n.6, p.778-781, 1958.

Pesq. agropec. bras., Brasília, v.35, n.10, p.2043-2050, out. 2000 
SRIVASTAVA, S.C.; SINGH, J.S. Microbial C, N and P in dry tropical forest soils: effects of alternate landuses and nutrient flux. Soil Biology \& Biochemistry, Oxford, v.23, n.2, p.117-124, 1991.

SYLVESTER-BRADLEY, R.; ASAKAWA, N.; LA TORRACA, S.; MAGALHÃES, F.M.M.; OLIVEIRA, L.; PEREIRA, R.M. Levantamento quantitativo de microrganismos solubilizadores de fosfatos na rizosfera de gramíneas e leguminosas forrageiras na Amazônia. Acta Amazônica, Manaus, v.12, n.1, p.15-22, 1982.
WOLLUM, A.G. Cultural methods for soil microorganisms. In: PAGE, A.L.; MILLER, R.H.; KEENEY, D.R. (Ed.). Methods of soil analysis. Madison : Soil Science Society of America, 1982. p.781-802.

YOUNG, C.C. Effects of phosphorus-solubilizing bacteria and vesicular-arbuscular mycorrhizal fungi on the growth of tree species in subtropical-tropical soils. Soil Science and Plant Nutrition, Tokyo, v.36, n.2, p.225-231, 1990. 